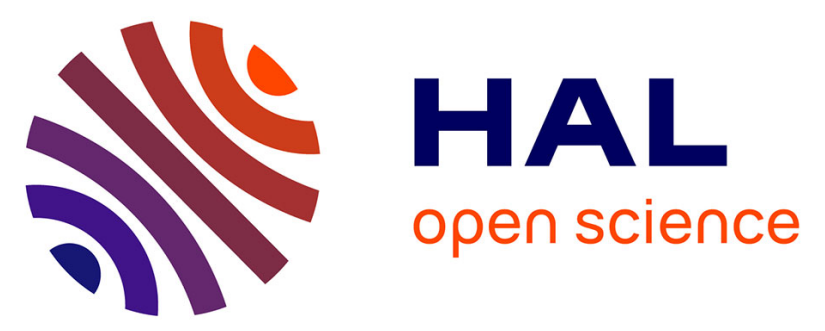

\title{
Surprising Differences of Alkane C-H Activation Catalyzed by Ruthenium Nanoparticles: Complex Surface-Substrate Recognition?
}

Niels Rothermel, Donia Bouzouita, Tobias Röther, Torsten Gutmann, Iker Del rosal, Simon Tricard, Romuald Poteau, Bruno Chaudret, Hans-Heinrich Limbach, Gerd Buntkowsky

\section{To cite this version:}

Niels Rothermel, Donia Bouzouita, Tobias Röther, Torsten Gutmann, Iker Del rosal, et al.. Surprising Differences of Alkane C-H Activation Catalyzed by Ruthenium Nanoparticles: Complex SurfaceSubstrate Recognition?. ChemCatChem, 2018, 10 (19), pp.4243-4247. 10.1002/cctc.201801022 . hal02296026

\section{HAL Id: hal-02296026 \\ https://hal.science/hal-02296026}

Submitted on 24 Sep 2019

HAL is a multi-disciplinary open access archive for the deposit and dissemination of scientific research documents, whether they are published or not. The documents may come from teaching and research institutions in France or abroad, or from public or private research centers.
L'archive ouverte pluridisciplinaire HAL, est destinée au dépôt et à la diffusion de documents scientifiques de niveau recherche, publiés ou non, émanant des établissements d'enseignement et de recherche français ou étrangers, des laboratoires publics ou privés. 
C-H Activation

\title{
Surprising Differences of Alkane C-H Activation catalyzed by Ruthenium Nanoparticles: Complex Surface-Substrate Recognition?**
}

\author{
Niels Rothermel ${ }^{\#}$, Donia Bouzouita , Tobias Röther, Torsten Gutmann, Iker de Rosal, Simon Tricard, \\ Romuald Poteau, Bruno Chaudret*, Hans-Heinrich Limbach*, and Gerd Buntkowsky*
}

\begin{abstract}
The activation of $C$ - $H$ bonds of alkanes remains a major challenge for chemistry. In a series of deuteration experiments with $D_{2}$ in contact with bis-(diphenylphosphino)butane (dppb) stabilized ruthenium nanoparticles (liquid substrates, $60^{\circ} \mathrm{C}, 6$ bar $\mathrm{D}_{2}$ ) we have observed a surprisingly large reactivity of cyclopentane as compared to cyclohexane and other alkanes. DFT calculations using a ligandfree $\mathrm{Ru}_{13} \mathrm{H}_{17}$ model cluster as catalyst indicate oxidative $\mathrm{C}-\mathrm{H}$ cleavage of the bound substrates as rate limiting reaction step. They also indicate similar binding and activation enthalpies of reactions of cyclopentane and cyclohexane.
\end{abstract}

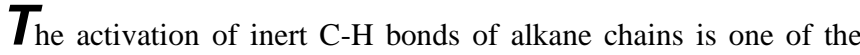
major challenges for chemists. What nature achieves with high efficiency in enzymatic conversions ${ }^{[1]}$ is still nearly not feasible in technical reactions, namely regio- and stereo selective activation of alkanes. The highest value in mastering this field of catalysis refers to the world's crude oil reserves, which constitute up to $50 \%$ alkanes. ${ }^{[2]}$ If a C-H bond in an alkane could be regarded as a precursor to a hydroxyl-, carboxy- or an amine group for example, the large alkane fraction in the crude oil would feed the pool of industrial base chemicals. Thus, heterogeneous catalysis has long studied the activation of hydrocarbons on metal surfaces with typical reactions such as alkane hydrogenolysis. In these studies, H/D exchange has been used as a test of reactivity of the hydrocarbons. In this respect, when explicitely mentioned no real difference in reactivity was found for cyclohexane and cyclopentane..$^{[3,4,5,6]}$ In solution, the research field of $\mathrm{C}-\mathrm{H}$ activation in alkanes was established by the pioneering work of Shilov et al..$^{[7]}$ and was tackled mostly by organometallic chemistry since then. ${ }^{[8]}$
Whereas previous $\mathrm{C}-\mathrm{H}$ activation studies employed homogeneous catalysis, some of us have explored the use of transition metal Ru-nanoparticles separated by organic protecting ligands as homogeneous and heterogeneous catalysts. ${ }^{[9,10,11]}$ Recently, transition metal nanoparticles have also been created on well-defined metal surfaces and studied with respect to their catalytic activity. ${ }^{[12]}$ Ligand separated nanoparticles catalyse a number of chemical reactions, e.g. hydrogenation of olefins and C-C activation. ${ }^{[13]} \mathrm{In}$ combined ${ }^{1} \mathrm{H}$ gas phase and solid state ${ }^{2} \mathrm{H}$ NMR studies ${ }^{[14,15]}$ some of us have shown that these particles contain surface hydrogens which can be replaced by deuterons by exposure to $\mathrm{D}_{2}$ gas, resulting in the release of HD. However, it was also observed that $\mathrm{CH}_{2}$ groups of organic ligands such as hexadecylamine (HDA) were partially deuterated, a process which could only take place via C-H activation.

As $\mathrm{H} / \mathrm{D}$ exchange is almost isoenergetic to the insertion of functional groups ${ }^{[16]}$ it can be used as in heterogeneous catalysis, as a straightforward test for C-H bond activation. ${ }^{[17]}$ Recently some of us demonstrated that $\mathrm{Ru}$ nanoparticles could also catalyze in organic or aqueous solvents the site- and stereo selective deuteration of a variety of aza compounds. ${ }^{[18,19]}$ In the present study we explore the C-H activation potential of $\mathrm{Ru}$ nanoparticles towards alkanes via $\mathrm{H} / \mathrm{D}$ exchange and discovered much to our surprise a large difference of reactivity between cyclopentane and cyclohexane.

[*] N. Rothermel, T. Röther, Dr. T. Gutmann, Prof. Dr. G. Buntkowsky

Eduard-Zintl-Institut für Anorganische und Physikalische Chemie

Technische Universität Darmstadt

Alarich-Weiss-Str. 4, 64287 Darmstadt (Germany)

E-mail: Gerd.Buntkowsky@chemie.tu-darmstadt.de Homepage: http://www.chemie.tu-darmstadt.de/buntkowsky

Prof. Dr. H. H. Limbach

Institut für Chemie und Biochemie

Freie Universität Berlin

Takustr. 3, 14195 Berlin (Germany)

E-mail: limbach@chemie.fu-berlin.de

Dr. I. de Rosal, Dr. R. Poteau, D. Bouzouita, Dr. B. Chaudret

LPCNO; Laboratoire de Physique et Chimie de Nano-

Objets

UMR 5215 INSA-CNRS-UPS, Institut National des Sciences Appliquées

135, Avenue de Rangueil, 31077 Toulouse (France)

E-mail: chaudret@insa-toulouse.fr

[**] This research was supported by the Deutsche Forschungsgemeinschaft under contract Bu-911-22-1. IdR and RP thank the HPCs CALcul en Mldi-Pyrénées (CALMIP-HYPERION grant P1415) and the Grand Equipement National de Calcul Intensif (GENCI-TGCC, grant A0010810168).

[\#] These authors contributed equally to this work 

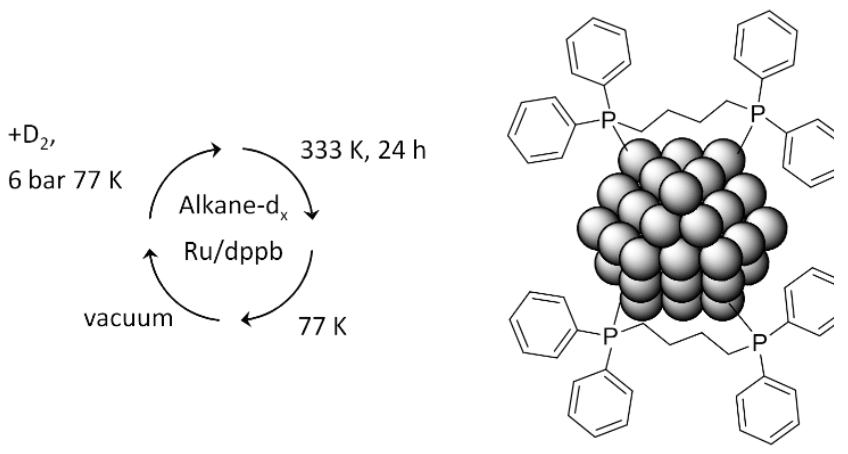

$\mathrm{Ru} / \mathrm{dppb}$

Scheme 1: Deuteration experiments performed of alkanes with 6 bar $D_{2}$ and $\mathrm{Ru} / \mathrm{dppb}$ nanoparticles as catalyst using different batch reaction cycles.

We choose bis-(diphenylphosphino)butane (dppb) stabilized ruthenium nanoparticles as heterogeneous catalyst, a system which is synthetically well established and can be regarded as a prototype for a hybrid of a heterogeneous and homogeneous catalyst. We first studied cyclopentane and cyclohexane as model substrates, since methylene groups in cyclic alkanes are the most reactive ones towards C-H activation. ${ }^{[20]}$ We then expanded our investigation to $n$-pentane, $n$-octane and iso-pentane as representatives for linear and branched alkanes. We chose heterogeneous liquid-solid reaction conditions by bringing the MNPs, synthesized as described previously, ${ }^{[2,22,23]}$ in direct contact with the liquid substrates as well as gaseous $\mathrm{D}_{2}$ and omitted a solvent. Mild conditions were used ( $333 \mathrm{~K}, 1$ or $2 \mathrm{ml}$ liquid alkane in a total volume of $95 \mathrm{~mL}$ containing 6 bar $\mathrm{D}_{2}$ gas). Generally, several batch cycles were performed, during typically $24 \mathrm{~h}$. After each cycle the samples were frozen to $77 \mathrm{~K}$ and the hydrogen gas mixture removed in vacuo and fresh $\mathrm{D}_{2}$ gas added for a new reaction cycle at $333 \mathrm{~K}$. At the end, mass spectra were taken to analyze the progress of alkane deuteration. The results are assembled in Table 1.

Table 1. Deuterium fractions of selected liquid alkanes after reaction with $\mathrm{D}_{2}$ in contact with Rudppb nanoparticles

\begin{tabular}{ccccccc}
\hline substrate & $\begin{array}{c}\text { boiling } \\
\text { point } \\
/ \mathrm{K}\end{array}$ & $\begin{array}{c}\text { substrate } \\
\text { volume/ } \\
\mathrm{ml}\end{array}$ & $\begin{array}{c}\text { batch } \\
\text { cycles }\end{array}$ & $\begin{array}{c}\text { reaction } \\
\text { time }\end{array}$ & $\begin{array}{c}\text { deuterium } \\
\text { fraction }\end{array}$ & $\begin{array}{c}\text { average } \\
\text { number } \\
\text { of D }\end{array}$ \\
\hline cyclopentane & & 1 & 3 & $24 \mathrm{~h}$ & $16.2 \%$ & 1.6 \\
cyclopentane & 322.4 & 1 & 5 & $24 \mathrm{~h}$ & $40.2 \%$ & 4.0 \\
cyclopentane & & 2 & 1 & $6 \mathrm{~d}$ & $6.2 \%$ & 0.6 \\
cyclohexane & 353.9 & 1 & 3 & $24 \mathrm{~h}$ & $0.65 \%$ & 0.08 \\
n-pentane & 309.3 & 1 & 3 & $24 \mathrm{~h}$ & $0.80 \%$ & 0.1 \\
iso-pentane & 301.0 & 1 & 3 & $24 \mathrm{~h}$ & $0.48 \%$ & 0.06 \\
n-octane & 398.8 & 1 & 3 & $24 \mathrm{~h}$ & $0.76 \%$ & 0.14
\end{tabular}

[a] Approximate values not corrected for the presence of ${ }^{13} \mathrm{C}$. For further reaction conditions see text. a)

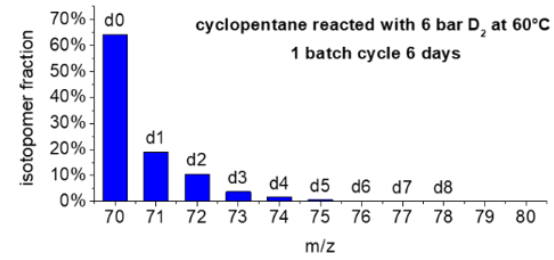

b)

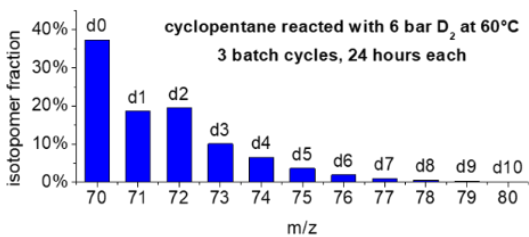

c)

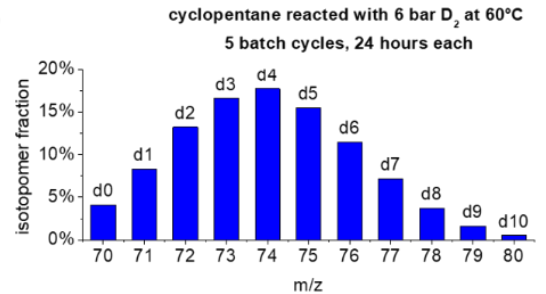

d)

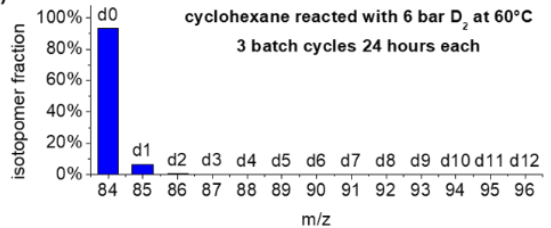

Figure 1: Isotopomer fraction patterns obtained from mass spectra for deuteration experiments on the substrates cyclopentane (a-c) and cyclohexane (d).

Fast deuteration of cyclopentane and slow deuteration of other alkanes. The isotopomer fraction patterns obtained from mass spectra of cyclopentane after 1, 3 and 5 reaction cycles are depicted in Figure 1a to $1 \mathrm{c}$. The spectra show in addition to the mole peak of the substrate cyclopentane- $d_{0}$ (mass $70 \mathrm{~m} / \mathrm{z}$ ) additional peaks of partially deuterated isotopologues, up to cyclopentane- $d_{10}$. After 3 batch cycles, cyclopentane- $d_{0}$ still dominates, but cyclopentane- $d_{2}$ is dominantly formed. We also conducted an experiment with $2 \mathrm{ml}$ substrate with only one batch cycle, but with a reaction time of 6 days. It resulted in an exchange of only $6.3 \%$ of the hydrogen atoms, where the initial dominance of cyclopentane- $d_{l}$ was gone. After 5 batch cycles, cyclopentane- $d_{4}$ becomes the dominant species. Thus, an excellent deuteration fraction of $40 \%$ is achieved in relatively mild conditions.

Previously, for H/D exchange of cyclopentane on metal surfaces a preference for the formation of the $d_{5}$-isotopologue was observed where all hydrogen atoms of one side the cyclopentane ring are exchanged. ${ }^{[24,25,26]}$ The finding of the dominance of cyclopentane- $d_{2}$ in the initial reaction stages indicates then that the incorporation of two deuterons is more probable than of one deuteron. That means that in the case of $\mathrm{Ru}$-nanoparticles two $\mathrm{C}-\mathrm{H}$ bonds can be activated during a single substrate binding process to surface $\mathrm{Ru}$. That could lead to the formation of $\mathrm{CD}_{2}$ groups or to two separate $\mathrm{CD}$ groups.

In the case of the other substrates, $n$-pentane, $n$-octane, isopentane, cyclohexane, the number of batch cycles was reduced to three for convenience, as this is sufficient to obtain information about the catalytic activity. Compared to cyclopentane, for all the other alkanes, very low turnovers are observed and at best a single deuterium atom is incorporated (Table 1). As an example, the details 
of the mole peak part of the mass spectrum of the cyclohexane experiment are depicted in Figure 1d.

This much more efficient deuteration of cyclopentane compared to the other alkanes was very surprising: Under energetic considerations such a difference is not to be expected since all $\mathrm{C}-\mathrm{H}$ bonds in alkanes have comparable cleavage energies between 402 and $439 \mathrm{~kJ} / \mathrm{mol} .{ }^{[27,28]}$ In particular, cyclopentane $(395-403 \mathrm{~kJ} / \mathrm{mol})$ and cyclohexane $(400 \mathrm{~kJ} / \mathrm{mol})$ are quite similar with respect to $\mathrm{C}-\mathrm{H}$ bond dissociation energies. ${ }^{[29]}$ Considering the general reactivity order for $\mathrm{H} / \mathrm{D}$ exchange in alkanes, which attributes the highest activity to C$\mathrm{H}$ groups in cycloalkanes, ${ }^{[20]}$ one would anticipate a similar reactivity of cyclopentane and cyclohexane.

To exclude trivial causes of the effect, we first checked the boiling points of the substrates included in Table 1, but no influence on the deuterium fraction achieved could be established. Next, we investigated the deuteration of cyclopentane and cyclohexane under fully inert conditions ( $1 \mathrm{ml}$ liquid alkanes in a total volume of $90 \mathrm{~mL}$ containing 4 bar $\mathrm{D}_{2}$ gas, oxygen free environment) to exclude that a reaction of the catalyst with spurious oxygen present in the solvent or the atmosphere of the glove box accounts for the different efficiencies in deuteration. The obtained isotopomer patterns in Figure S1a,c clearly show that the difference in the deuteration efficiency is reproducible under idealized conditions $\left(333 \mathrm{~K}, 4\right.$ bar $\mathrm{D}_{2}$, degassed substrates). As further shown in Figure S1b,d, although the conversion to higher deuterated isotopomers increases with increasing temperature from $333 \mathrm{~K}$ to $373 \mathrm{~K}$, the pronounced difference between cyclopentane and cyclohexane is still present. These results show that the different deuteration efficiencies are of general nature and not the result of a spurious presence of oxygen.

Thermodynamic or kinetic reaction control? In the experiment with $2 \mathrm{~mL}$ cyclopentane that was performed with only one batch cycle and a reaction time of 6 days (Table 1) we noticed that the thermodynamic equilibrium was not yet reached. Assuming a statistical equilibrium, a deuterium fraction of about $18 \%$ is to be expected in a system with $2 \mathrm{~mL}$ cyclopentane $(21.1 \mathrm{mmol}, 211 \mathrm{eq} . \mathrm{H})$ and 6 bar $\mathrm{D}_{2}$ in $95 \mathrm{~mL}$ (23.4 mmol, 46.8 eq. D). It can, therefore, be concluded that the different substrate reactivities are not caused by equilibrium isotope effects. Thus, the results are kinetically controlled. Furthermore, it can be concluded that the low reactivity of cyclohexane is not a consequence of diffusion problems caused by molecular size. Preliminary experiments performed on toluene, which exhibits a similar calculated van der Waals volume as cyclohexane (toluene $=98.9 /$ cyclohexane $=101.9 \AA^{3}$ ), ${ }^{[30]}$ indicate a much larger reactivity towards deuteration, i.e. toluene can readily access the surface and react. Thus, the ligand sphere of the particle does not act as a steric- or diffusion limiting barrier.

Reaction mechanism. In order to identify the rate limiting step in the $\mathrm{C}-\mathrm{H}$ activation the generally accepted reaction mechanism for the activation of alkanes by metal complexes is adapted in Scheme 2 to the case of alkane deuteration by transition metal nanoparticles.
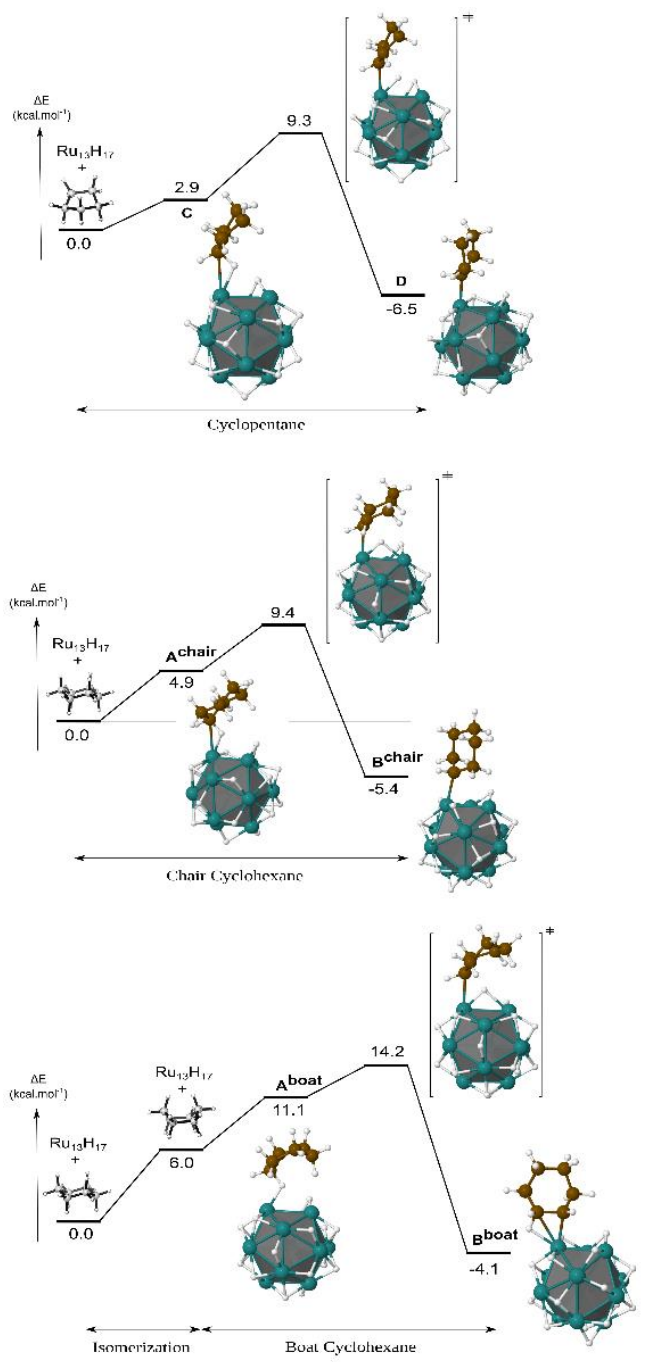

Scheme 2: C-H activation pathway for twist-boat cyclohexane, chair cyclohexane and cyclopentane at Ru cluster surface.

In the first step (see Scheme S1), surface hydride of the latter which contain a large number of defects such as edges, apexes and steps $^{[31]}$ that offer coordinatively unsaturated metal atoms - are deuterated releasing HD when they are exposed to $\mathrm{D}_{2}$ gas. ${ }^{[15]}$ In the second step, the alkane substrate forms an $\sigma$-complex with surface $\mathrm{Ru}$ atoms and transfers an $\mathrm{H}$ from $\mathrm{C}$ to $\mathrm{Ru}$ (Scheme $2 \mathrm{~b}$ ) corresponding to an oxidative cleavage a surface alkyl. As surface H/D exchange is fast, ${ }^{[15]}$ there is a great chance that in the backward reaction a D is transferred to $\mathrm{C}$. Finally, the deuterated product is released from the surface.

In several studies, Ball et al. ${ }^{[32,33,34]}$ have elucidated the structures of $\sigma$-complexes of cyclohexane, cyclopentane and $n$-pentane with $\operatorname{Re}$ fragments by NMR spectroscopy. They observed very similar structures of the $\mathrm{C}-\mathrm{H}-\mathrm{Re}$ moiety. Moreover, DFT calculations indicated similar free energies of activation of $\mathrm{H}$ transfer from $\mathrm{C}$ to Re. ${ }^{[35]}$ That is in line with previous DFT calculations of the pathway of deuteration of compounds with amino groups using $\mathrm{Ru}$ nanoparticles. ${ }^{[18,19]}$

In order to check whether the oxidative cleavage of the $\sigma$ complex is the rate limiting step also in the deuteration of alkanes by RuNP we have carried out DFT calculations at the DFT-PBE level of theory. Thus, the $\mathrm{C}-\mathrm{H}$ activation of the cyclopentane and of the two more stable conformations of cyclohexane (twist-boat and chair) has been studied using a $0.5 \mathrm{~nm}$ ruthenium cluster with $1.4 \mathrm{H}$ atoms per $\mathrm{Ru}$ surface atom $\left(\mathrm{Ru}_{13} \mathrm{H}_{17}\right)$ as RuNP model. The same strategy has also been successfully used in previous studies to shed light both on the enantiospecific $\mathrm{C}-\mathrm{H}$ activation of an isopropylamine using 
RuNPs as catalysts ${ }^{[19]}$ and to compare the $\mathrm{C}-\mathrm{C}$ vs. $\mathrm{C}-\mathrm{H}$ activation of ethane at the surface of RuNPs. ${ }^{[36]}$ In all the cases (Scheme 2), the C$\mathrm{H}$ activation reaction begins by the formation of an adduct ( $\mathbf{A}^{\text {chair }}$, $\mathbf{A}^{\text {boat }}$ and $\mathbf{C}$ ) that exhibits a so-called agostic interaction, i.e., a threecenter two electron bond between a C-H bonding orbital of one of the $\mathrm{CH}_{2}$ groups lifted out of the plane of the ring and an empty metal orbital. The increase of the $\mathrm{C}-\mathrm{H}$ bond length by around $0.07 \AA$, independently of the reactant, is indicative of the formation of this agostic interaction. For the chair cyclohexane and cyclopentane it is worth noting that the $\mathrm{C}-\mathrm{H}$ bond activation is a kinetically very accessible process with the same activation barrier of $\sim 9.4 \mathrm{kcal} / \mathrm{mol}$. From a thermodynamic point of view, the $\mathrm{C}-\mathrm{H}$ bond breaking is also very similar and slightly favored, between -5.4 and $-6.5 \mathrm{kcal} / \mathrm{mol}$. The $\mathrm{C}-\mathrm{H}$ bond activation barrier in the twist boat conformation of cyclohexane was found to be $14.2 \mathrm{kcal} / \mathrm{mol}$ which is somewhat larger than calculated for the other species. That difference may be attributed to the intrinsic isomerization cost between the chair and twist-boat conformations.

Unfortunately, we were not able in this study to explore whether different contributions to the binding and/or activation entropies are responsible for the different reactivity of cyclopentane with respect to the other alkanes. That could arise from a different reduction of the number of molecular configurations in the $\sigma$-complexes and the transition states with respect to the unbound states. Such a "ligand configurational entropy" has been demonstrated in the case of binding of small flexible molecules to proteins. ${ }^{[37]}$ This reduction of the configurational space is symbolized schematically in Scheme $2 b$ for the binding and the reaction of the central $\mathrm{C}-\mathrm{H}$ group of $n$-pentane to $\mathrm{Ru}$. In other words, in the transition state of the oxidative cleavage only certain molecular conformations may be reactive. That circumstance depends both on the properties of the substrate molecules as well as on the details of the configuration of the catalytic $\mathrm{Ru}$ atoms and the adjacent organic stabilizing ligands. However, ligand configurational entropy contributions may not play the decisive part of the different reactivity of cyclopentane and of the other alkanes.

[1] J. B. Van Beilen, Z. Li, W. A. Duetz, T. H. M. Smits, B. Witholt, Oil Gas Sci. Technol. 2003, 58, 427-440.

[2] B. A. Arndtsen, R. G. Bergman, T. A. Mobley, T. H. Peterson, Acc. Chem. Res. 1995, 28, 154-162.

[3] H. C. Rowlinson, R. L. Burwell Jr., R. H. Tuxworth J. Phys. Chem., 1955, 59, 225-231.

[4] R. L. Burwell Jr., R. H. Tuxworth, J. Phys. Chem., 1956, 60, 1043-1049.

[5] R. L. Burwell Jr., B. K. C. Shim, H. C. Rowlinson, J. Am. Chem. Soc., 1957, 79, 5142-5148.

[6] R. L. Burwell Jr., K. Schrage, Discuss. Faraday Soc., 1966, 41, 215-222.

[7] A. E. Shilov, G. B. Shul'pin, Chem. Rev. 1997, 97, 2879-2932.

[8] R. H. Crabtree, J. Organomet. Chem. 2004, 689, 4083-4091.

[9] K. Philippot, B. Chaudret, Comptes Rendus Chim. 2003, 6, 10191034

[10] C. Pan, K. Pelzer, K. Philippot, B. Chaudret, F. Dassenoy, P. Lecante, M. J. Casanove, J. Am. Chem. Soc. 2001, 123, 7584-93.

[11] T. Gutmann, I. del Rosal, B. Chaudret, R. Poteau, H.-H. Limbach, G. Buntkowsky, ChemPhyChem 2013, 14, 3026-3033.

[12] H. A. Aleksandrov, S. M. Kozlov, S. Schauermann, G. N. Vayssilov, K. M. Neyman, Angew. Chem. - Int. Ed. 2014, 53 , 13371-13375.

[13] J. García-Antón, M. R. Axet, S. Jansat, K. Philippot, B. Chaudret, T. Pery, G. Buntkowsky, H.-H. Limbach, Angew. Chem. Int. Ed. Engl. 2008, 47, 2074-8.

[14] T. Pery, K. Pelzer, G. Buntkowsky, K. Philippot, H. H. Limbach, B. Chaudret, Chemphyschem 2005, 6, 605-607.
Thus, our calculations derived for "ideal" alkane $/ \mathrm{Ru}_{13} \mathrm{H}_{17}$ model systems indicate similar binding and activation enthalpies of $\mathrm{C}-\mathrm{H}$ activation of cyclopentane and cyclohexane. It was not possible in the present study to explore whether different binding and activation entropies which could arise from a different conformational entropy decrease upon binding is the cause. Anyway, it might be possible that there are no major differences in these entropy terms.

As the differences between the $\mathrm{C}$ - $\mathrm{H}$ activation of cyclopentane and the other alkanes by RuNP are well reproducible, we have to conclude that the latter exhibit a specifically enhanced reactivity for cyclopentane which can, however, not be explained in terms of the "ideal" alkane/RuNP model. That means that the "real" nanoparticles do not only contain a complex surface with many defects and disordered ligands but also provide the possibility of specific intraand intermolecular primary and secondary interactions with substrates resulting in different reactivities for different substrates. In a way, the real RuNP behave in a similar way as substrate recognizing enzymes.

In conclusion, the liganded Ru-surface exhibits a specific recognition for cyclopentane whose origin is not yet understood, but must arise from a complex interplay of various intra- and intermolecular surface-substrate interactions, perhaps accompanied by different tunneling rates, owing to conformational changes in the course of the transfer reaction. Thus, the observation of the structure-dependent $\mathrm{C}-\mathrm{H}$ activation of alkanes by RuNP opens up a lot of new questions and challenging tasks for the future, in particular the vision of preferentially catalyzing certain reactions by suitable modifications of the nanoparticle-ligand interface.

Received: ((will be filled in by the editorial staff))

Published online on ((will be filled in by the editorial staff))

Keywords: Alkane C-H activation, deuterium isotopic labeling, catalysis, nanoparticles

[15] H. H. Limbach, T. Pery, N. Rothermel, B. Chaudret, T. Gutmann, G. Buntkowsky, Phys. Chem. Chem. Phys. 2018, 20 http://dx.doi.org/ 10.1039/C7CP07770J in press.

[16] W. D. Jones, Acc. Chem. Res. 2003, 36, 140-146.

[17] A. Di Giuseppe, R. Castarlenas, L. A. Oro, Comptes Rendus Chim. 2015, 18, 713-741.

[18] G. Pieters, C. Taglang, E. Bonnefille, T. Gutmann, C. Puente, J.-C. Berthet, C. Dugave, B. Chaudret, B. Rousseau, Angew. Chem. Int. Ed. Engl. 2014, 53, 230-234.

[19] C. Taglang, L. M. Martínez-Prieto, I. Del Rosal, L. Maron, R. Poteau, K. Philippot, B. Chaudret, S. Perato, A. Sam Lone, C. Puente, C. Dugave, B. Rousseau,G. Pieters, Angew. Chemie - Int. Ed. 2015, 54, 10474-10477.

[20] M. Lersch, M. Tilset, Chem. Rev. 2005, 105, 2471-2526.

[21] F. Novio, K. Philippot, B. Chaudret, Catal. Letters 2010, 140, 1-7.

[22] S. Kinayyigit, P. Lara, P. Lecante, K. Philippot, B. Chaudret, Nanoscale 2014, 6, 539-46.

[23] P. Lara, T. Ayvalı, M.-J. Casanove, P. Lecante, A. Mayoral, P.-F. Fazzini, K. Philippot, B. Chaudret, Dalton Trans. 2013, 42, 37282.

[24] T. Baird, E. J. Kelly, W. R. Patterson, J. J. Rooney, J. Chem. Soc. Chem. Commun. 1992, 1431.

[25] M. K. Oudenhuijzen, S. Van Dommele, J. A. Van Bokhoven, D. C. Koningsberger, J. Catal. 2003, 214, 153-164.

[26] M. Oudenhuijzen, J. . van Bokhoven, D. . Koningsberger, J. Catal. 2003, 219, 134-145.

[27] R. H. Crabtree, J. Chem. Soc. Dalt. Trans. 2001, 2437-2450.

[28] D. Pla, M. Gómez, ACS Catal. 2016, 6, 3537-3552.

[29] Z. X. Tian, A. Fattahi, L. Lis, S. R. Kass, J. Am. Chem. Soc. 2006, 128, 17087-17092. 
[30] Calculator plugins of the Marvin Suit were used for structure property calculations, Marvin 16.10.3 2016, ChemAxon.

[31] T. Gutmann, E. Bonnefille, H. Breitzke, P.-J. Debouttière, K. Philippot, R. Poteau, G. Buntkowsky, B. Chaudret, Phys. Chem. Chem. Phys. 2013, 15, 17383-94.

[32] S. Geftakis, G. E. Ball, J. Am. Chem. Soc. 1998, 120, 9953-9954.

[33] D. J. Lawes, T. A. Darwish, T. Clark, J. B. Harper, G. E. Ball, Angew. Chemie Int. Ed. 2006, 45, 4486-4490.

[34] D. J. Lawes, S. Geftakis, G. E. Ball, J. Am. Chem. Soc. 2005, 127,
4134-4135.

[35] A. L. Pitts, A. Wriglesworth, X. Z. Sun, J. A. Calladine, S. D.; Zarić, M. W. George, M. B. Hall, J. Am. Chem. Soc. 2014, 136, 8614-8625.

[36] M. Mercy, I. del Rosal, R. Poteau, Nanotech 2013 Conference Proceedings, Taylor \& Francis CRC Press Inc, 2013, 2, 615-618.

[37] C. A. Chang, W. Chen, M. K. Gilson, Proc. Natl. Acad. Sci. U. S. A. 2007, 104, 1534-1539. 
